\title{
20 Jahre IVDK - \\ der Wächter hat seine Mission erfüllt
}

K

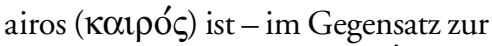

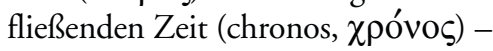
die günstige Gelegenheit, die besondere Chance, der rechte Augenblick, den es zu ergreifen gilt. Das Jahr 1987 war für die Allergologie eine solche Zeit: Die Politik hatte ,massive Wissenslücken " erkannt, und viel Geld in die Hand genommen, um auf verschiedenen Feldern - u. a. auch im Bereich der Epidemiologie - die Forschung voranzubringen. Bis zum Jahre 1994 waren 37 Vorhaben mit 36 Millionen DM gefördert worden. Eines dieser Projekte war der „Informationsverbund Dermatologischer Kliniken (IVDK) zur Dokumentation und wissenschaftlichen Auswertung der Kontaktallergien“, der vom 1. November 1988 bis zum 31. Dezember 1994 mit insgesamt 2.543.265,27 DM unterstützt wurde.

In einer weiteren Hinsicht war das Jahr 1987 vom Kairos geprägt: Fast zeitgleich zur Vorstellung des IVDK-Pro-

„Der Wert der Epidemiologie steht und fällt mit der Validität der erhobenen Einzeldaten.“ jektes am 2. April in Berlin konstituierte sich auf Initiative von Prof. Dr. Peter Frosch, Heidelberg, am 26. Mai die Deutsche Kontaktallergie-Gruppe (DKG). Ausgehend von der gemeinsamen Antragstellung mit Prof. Dr. Peter Frosch, Prof. Dr. Hellmut Ippen und Dr. Peter Pietrzyk am 16. März 1988 entwickelte sich eine fruchtbare Kooperation zwischen IVDK und DKG. Für ein Projekt der klinischen Epidemiologie wie dem IVDK ist diese Zusammenarbeit mit der DKG, die für die Kontaktallergie die diagnostischen Qualitätsstandards erarbeitete, von essenzieller Bedeutung, denn der Wert der Epidemiologie steht und fällt mit der Validität der erhobenen Einzeldaten.

Nun, 20 Jahre nach Projektbeginn, ist die Gelegenheit gegeben, die Ergebnisse des Projektes IVDK zu besichtigen. Einen kleinen Einblick bieten - pars pro toto - die in diesem Heft veröffentlichten Arbeiten ab Seite 611. Wenn in der Projektausschreibung des Bundesministeriums für Forschung und Technologie seinerzeit gefordert wurde: „In Anträgen zu epidemiologischen Studien ist der zu erwartende Nutzen für Prävention und Krankheitsbekämpfung ausführlich zu erläutern“, so kann

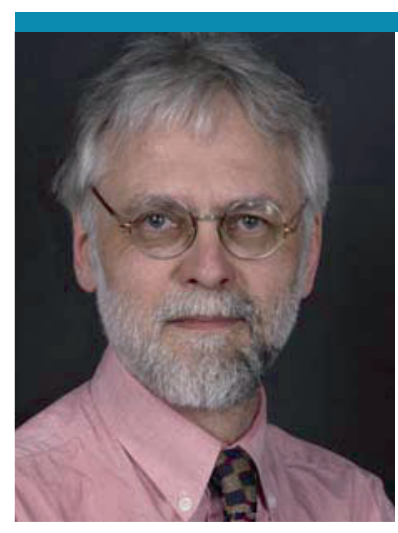

\section{Prof. Dr. Axel Schnuch, Leiter des Informationsverbundes Dermatologischer Kliniken (IVDK) an der Universitäts- Hautklinik Göttingen}

man heute ganz unbescheiden feststellen: „Mission erfüllt". Der IVDK ist der ihm schon im Jahre 1987 von Prof. Dr. Wolfgang Schmutzler zugewiesenen „Wachhund“-Funktion nachgekommen. Ein Leitmotiv war, zur Versachlichung der Diskussion beizutragen, im Spannungsfeld von (Über-)Regulation und Positionen der Industrie sowie der Medien

Obwohl nun, im Jahre 2008, die Zeichen wieder günstig zu sein scheinen (Kampagne „Deine Haut. Die wichtigsten $2 \mathrm{~m}^{2}$ Deines Lebens" oder „Nationaler Aktionsplan gegen Allergien" des Ministers Seehofer), so ist man über symbolische Politik kaum hinaus gelangt, meilenweit entfernt von der zupackenden Art der Politik der 80er Jahre. Und wenn man bedenkt, dass die Verbraucherpolitik sehenden Auges auf ein Humanexperiment großen Stils zusteuert - wenn ab 2009 beziehungsweise 2013 prädiktive Tierversuche verboten sein werden und der Verbraucherschutz blauäugig auf In-vitro-Experimente
„Die Verbraucherpolitik steuert mit dem Verbot prädiktiver Tierversuche auf ein Humanexperiment großen Stils zu." setzt -, dann wird die Über-

wachung der Kontaktallergien durch den IVDK das einzige Instrument sein, das die (Un-)Sicherheit von neuen Stoffen tatsächlich belegt.

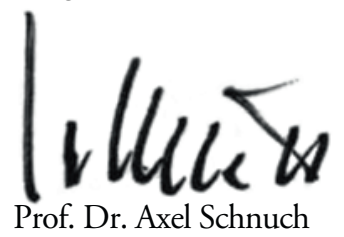

